\title{
The design process of the complex Special Utility Vehicle using the methodical design approach
}

\author{
Fatma Y. ÇAVDAR*, Hüseyin R. BÖRKLÜ**, Kadir ÇAVDAR*** and H. Kürşad SEZER** \\ *Department of Mechanical Engineering, Inst. of Science, Uludag University, 16059 Bursa, Turkey \\ **Department of Industrial Design Engineering, Gazi University, 06500 Ankara, Turkey \\ E-mail: kursadsezer@gazi.edu.tr

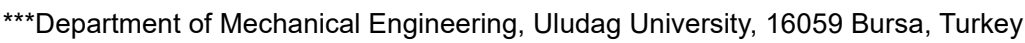

Received: 17 April 2019; Revised: 27 August 2019; Accepted: 26 September 2019

\begin{abstract}
This paper describes the designing and manufacturing process of a complex special utility vehicle (SUV) using the methodical design approach for which the basics were explained decades ago in Germany. The application steps of the design methodology with comprehensive data are clearly outlined and the experiences gained during the project along with the authors' experiences in design research and design practice over 25 years are generously shared. This paper contributes to the methodical approach laid by Pahl \& Beitz with an industrial example proving its applicability in real engineering design applications. The proposed solutions for difficulties encountered in the process are especially valuable and applicable for SMEs (small and medium-sized enterprises) in the field. Such details are reported with comprehensive discussions in this paper.
\end{abstract}

Keywords : Design methodology, SUV vehicle design, Systematic design, Design practice, Systematic product development

\section{Introduction}

Designers play a significant role in small and big companies, but are often confronted with tasks containing problems they cannot solve immediately. Such problem-solving tasks in different application areas and at different levels of concrete realisation of products are characteristics of a designer's work. These design problems usually have the typical characteristics of complexity and uncertainty. Many design approaches have been introduced to deal with such difficulties and some papers especially explained the vehicle and its parts design processes (Kim et al., 2014; Chen et al., 2015; Ma et al., 2013, Sahoo et al., 2015; Yoon et al., 2013). The methodical design approach (MDA) has also been used to design engineering products recommending various special systematic methods for designers. According to the MDA, an engineer seeking design solutions for an engineering problem or task follows the steps outlined in Figure 1.

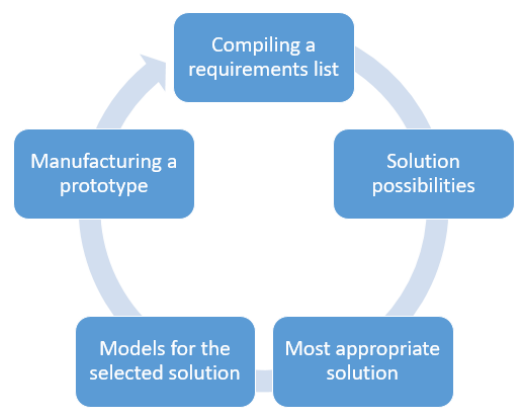

Fig. 1 Methodical Design Approach steps. 
With a brief outline viewing of Figure 1, one can see that the first step, 'compiling a requirement list', involves understanding and identifying the task with all details which is followed by searching for and recording solution possibilities. The most appropriate solution using suitable methods can then be selected. The designer will then create and manage the models for the selected solution and prepare for the manufacturing refinement phase. Finally, a prototype can be manufactured carrying out trials on the prototype leading to submission of it for serial manufacturing.

The process including all of these design steps has specific time period requirements. Historically time to market product development had been a lengthy process with considerable design-prototype iterations and significant cost involved. Today, however, the process can be accomplished in less and less time comparably with advanced CAD methods and rapid-prototyping technologies (3D printing). Despite these technological advances, successful designing of complex products requires systematic design approaches as it is affected by complex relationships of the above steps and with a wide variety of other factors such as state-of-the-art design, economics and the societal level of development (Pahl and Beitz, 1993; Cavdar, 2000).

In the MDA, the first and the foremost important step is definition of the task, creation of the requirements list and a task analysis. It should be noted that a task is different from a problem because the task imposes mental requirements with various means and methods available for assistance. An example is the design of a shaft with given loads, connecting dimensions and production methods (Pahl et al., 2007). In the last fifty years, many thorough studies have been carried out in order to clarify the steps between the task (input) and the product (output). The methods do not differ greatly from each other. The MDA, according to (Pahl and Beitz, 1993), includes many processing steps. Their approach introduced a methodology dividing the design process into its main phases of planning and clarifying the task, generating concepts, embodiment and detail design. These steps start with an explanation of the assignment and creation of a requirements list, continue with the search for solutions and evaluation steps, and end up with the authorisation for manufacturing (Cavdar, 2000). It is also relevant to mention here a proverb exchanged among designers: The very first decisions made on a process determine its results. The designer's knowledge and technological opportunities are of great importance for task analysis. This first step of MDA hence plays a significant role in the future of the design project and is definitely not a waste of time.

The MDA hence suggests a process which is founded on basic science, engineering information and experience. The designer searches for, determines and finds the solutions for a technical problem using creative mental activity. In order to find technical solutions, the designer also takes numerous criteria and limitations into consideration, e.g. affordability, manufacturability, eco-friendliness, restrictions of size or mass, etc. There are many difficulties and contradistinctions present in this process. It is possible to define the purposive optimisation process. Moreover, large numbers of requests and conflicts may arise. The results obtained at the end of the process should be within the relative optimal values (Babalik and Cavdar, 2014; Mayda and Choi, 2017).

The second foremost important step, the requirements list includes many descriptive sentences consisting of a number of criteria from costs to main functions of the product. The designer searches for solutions among physical rules and on technological levels, evaluates and compares the solutions and determines the optimal values within the limits of the requirements list. There is a great deal of work for designers in the areas of styling, material selection, sizing, selection of production method, etc. The MDA steps which are summarised above and especially the solution search methods have been presented in VDI 2222 and the literature (Rodenacker, 1991; Günther and Ehrlenspiel, 1999; Eder, 2006). Many other case studies (e.g. Heylighen and Bianchin, 2012; Burr et al., 2005) can be found which were carried out with the MDA. A number of publications have also stressed the importance of the systematic approach and its application (Blizzard and Klotz, 2012; Smith and Clarkson, 2005).

Industrial companies express a definite interest in the above outlined MDA and systematic design, especially when they are involved in original design or plan to introduce novel product development. Consequently, such design approaches are being widely accepted in industry, although this may involve only the application of individual methods as the need arises. In particular, a systematic approach is being adopted for the development of novel designs where it is necessary to generate unconventional ideas, that is, to fulfil new functions with new solutions. The MDA has scarcely been introduced at all process for adaptive or variant design which benefit more from computer support (Pahl et al., 2007). The special utility vehicle (SUV) which is considered here as a case study for MDA is a machine generally not 
used on the motorways; however, it is very advantageous for use by factories, airports, city parks and farms. The SUVs are slow-motion vehicles and can be used for special functions such as snow removal, tree planting, lifting, and carrying. The hydrostatic drive is generally implemented to the move and drive applications for these types of vehicles. Design and prototype of such complex vehicle with a large number of specific parts using the MDA is described here in detail. Whole design process was managed by only three mechanical engineers and the project completed in only 18 months with the aid of systematic MDA. The final CAD model and a photo of the manufactured SUV prototype are shown in Figure 2 .

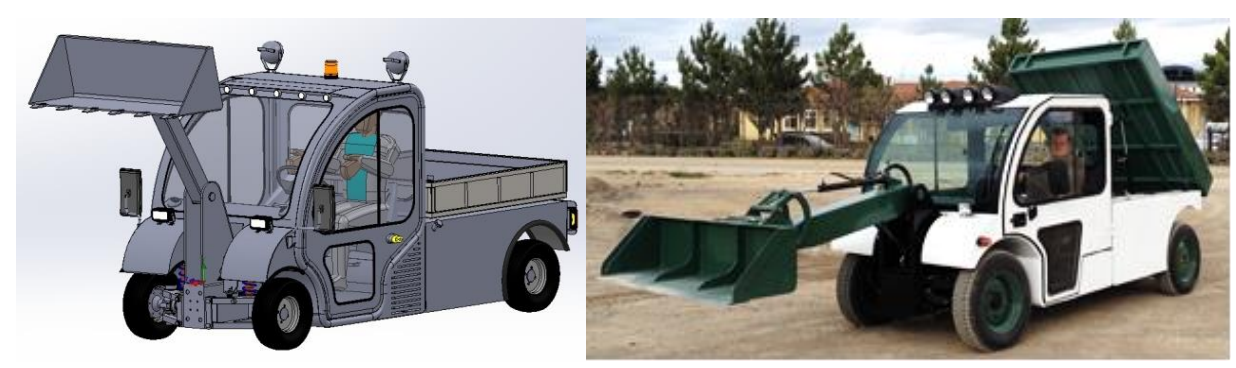

Fig. 2 The designed SUV CAD model and a photo of the manufactured prototype with principles of the MDA.

\section{The Overall Design Process}

The design process started with conceptual design phase which is then followed by the clarification of the task. For this purpose, a requirement list was created. This list for this particular project are given in Table 1 and extends to total of 34 items with 'must' demands and 'if possible' wishes. This list is based on all phases of concept design and development and has been amended several times in compulsory cases such as customer requests or legal enforcements. After final successful requirement list is approved, the frame of the design was drawn in the widest possible way where the steps of searching and elaboration of solutions were realized. A summary of the information about these steps are given in the following sections. The system function diagram is then generated as shown in Figure 3 after long iterations, effort and time. The function diagram includes independent sub-functions of the SUV. The data flows and associations of these sub-functions in E, M, S are also indicated on the diagram. Subsequently, important sub-function blocks are determined and possible solutions are placed in a schematic morphological matrix or chart. There are different sub solutions for the function on each line of the matrix. This phase is a real engineering work, and a number of solutions in accordance with the requirements list must be presented. Several functions such as drive (motor and hydraulic), load handling (lift, platform and other equipment), safe driving (safety belt and controls), stopping (hand brake), load stabilization (safety belts) and power transmission (grip, hydraulic circuit) and so on have been considered in this project.

Table 1 Sample items from the requirements list.

\begin{tabular}{|c|l|}
\hline \hline No & \multicolumn{1}{|c|}{ Requirements list for special utility vehicle } \\
\hline 1 & The production cost should be less than 20,000 Euros. \\
2 & Must carry at least $750 \mathrm{~kg}$ of cargo in the car and 2 people in the cabin. \\
3 & The mass should be less than $2000 \mathrm{~kg}$ (loaded). \\
4 & The main drive must be a diesel engine, but the vehicle must be hydrostatic controlled. \\
5 & The maximum speed of the vehicle should not exceed $40 \mathrm{~km} / \mathrm{h}$. \\
6 & The materials used must be suitable for indoor/outdoor use and environmentally friendly. \\
7 & It must be driven by automatic gear. \\
8 & Ergonomic design should be considered. \\
9 & It must be able to carry out at least 40 different tasks with extra attachments in the front and back sections. \\
10 & It must have an aesthetic appearance. A look that is dominated by green and white colors is the reason for \\
.. & preference. \\
$\ldots$
\end{tabular}


Fatma Y. Çavdar, Börklü, Kadir Çavdar and Sezer,

Journal of Advanced Mechanical Design, Systems, and Manufacturing, Vol.13, No.4 (2019)

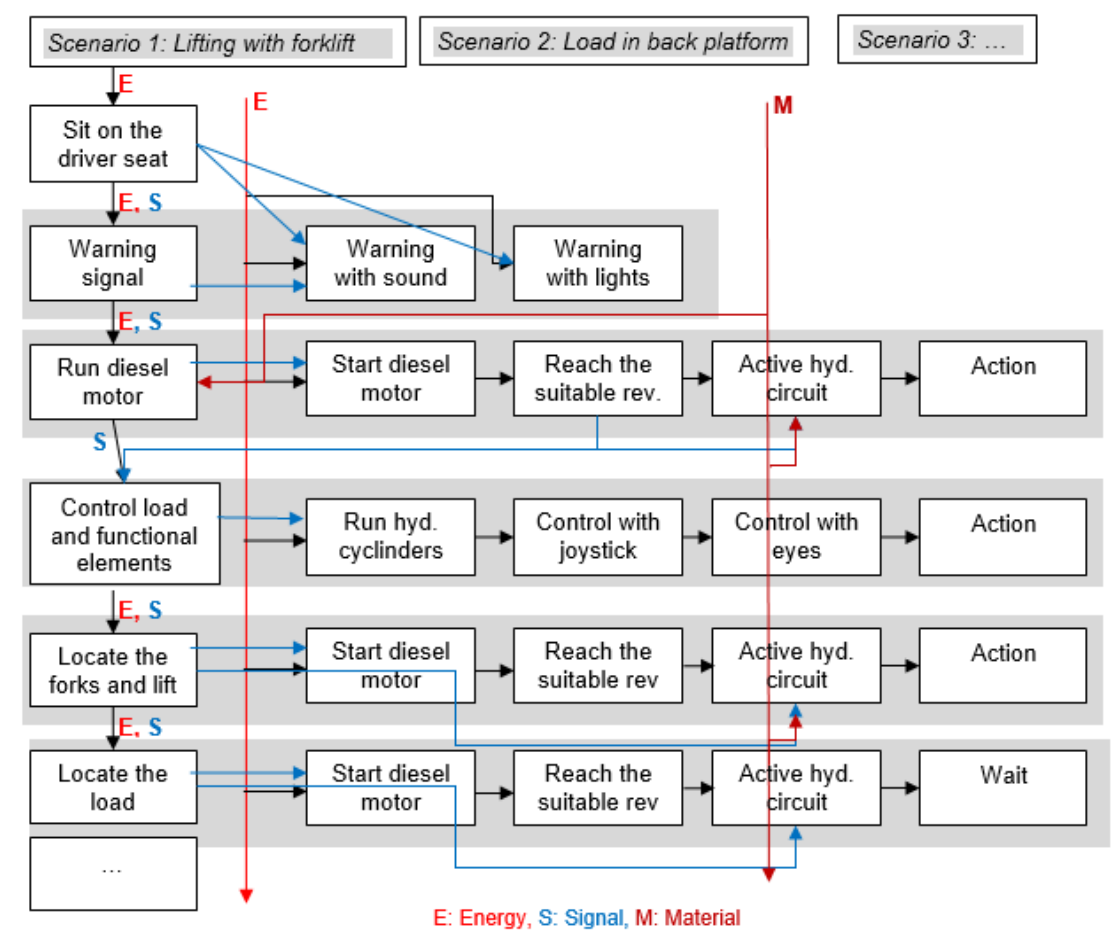

Fig. 3 The generated system function diagram (summarized) including independent sub-functions for a Special Utility Vehicle designed and manufactured using Methodical Design Approach.

The first stage and preliminary evaluation of the general designs that are formed by the sub-design combinations in the morphological matrix are done with the selection chart. In this chart, the criterions such as specification compliance, feasibility, reasonable cost etc. can be used. The goal is to select the most valuable solution and continue with the design process.

Table 2 The combination scheme for concept system design.

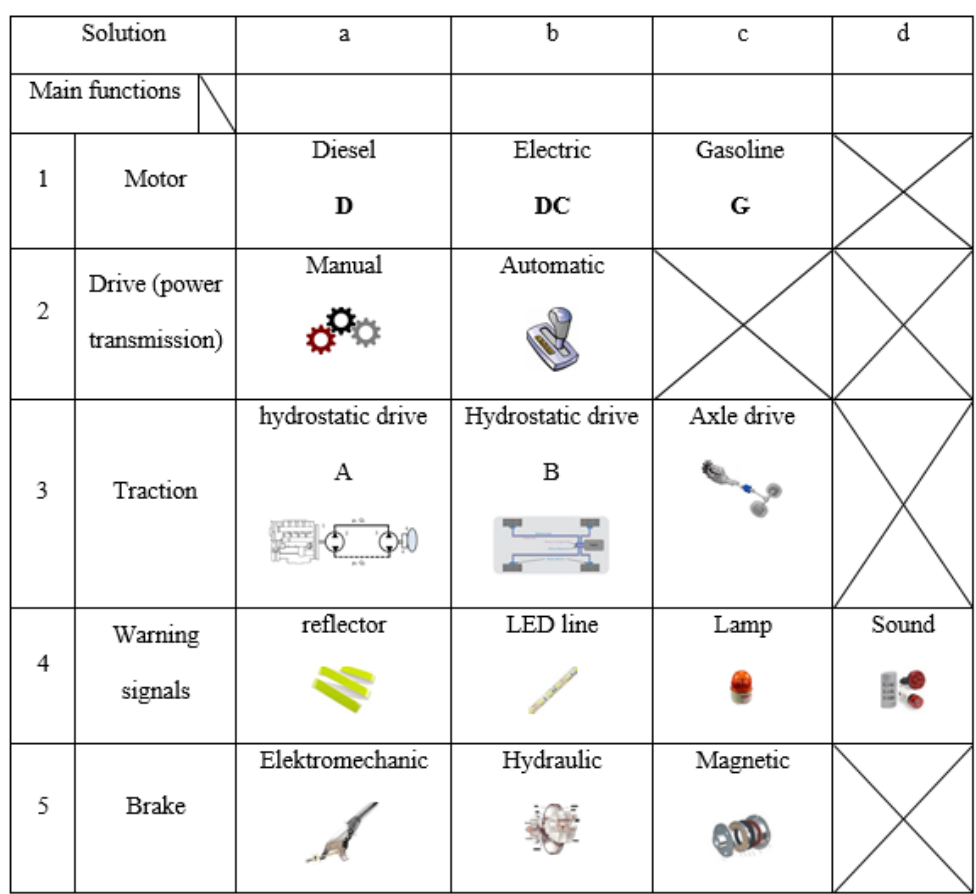




\subsection{Establishing Function Structures}

The system function diagram given in Figure 3 includes independent sub-functions of the SUV design. These subfunctions also specify the data flow and associations in E, M, S. Here, the important sub-function blocks are determined and a solution is put in a schematic morphological matrix or combination scheme matrix given in Table 2 . There are different sub-solutions for each line function (Pahl and Beitz, 1993). These functions are motor type, drive type (power transmission), traction, warning signals, brake, etc. The general design options obtained by various combinations of some sub-solutions including the morphological matrix are given in Table 3 as an example. Theoretically, 216 variants can be obtained from the morphological matrix in Table 2. However, the most important and suitable variants of these design concept variants are selected here. Four different conceptual designs (variants) were thus obtained, and this was sufficient for the design problem being conducted.

Table 3 General design options obtained by various combinations of some sub-solutions based on data in Table 2 .

\begin{tabular}{c|c}
\hline \hline Solutions $(S)$ & Combinations of sub-solutions \\
\hline S1 & $1-\mathrm{a}, 2-\mathrm{b}, 3-\mathrm{a}, 4-\mathrm{c}, 5-\mathrm{a}$ \\
S2 & $1-\mathrm{c}, 2-\mathrm{a}, 3-\mathrm{c}, 4-\mathrm{a}, 5-\mathrm{a}$ \\
S3 & $1-\mathrm{b}, 2-\mathrm{b}, 3-\mathrm{b}, 4-\mathrm{b}, 5-\mathrm{c}$ \\
S4 & $1-\mathrm{a}, 2-\mathrm{a}, 3-\mathrm{c}, 4-\mathrm{c}, 5-\mathrm{a}$ \\
\hline
\end{tabular}

Table 4 Selection chart for four drive combinations.

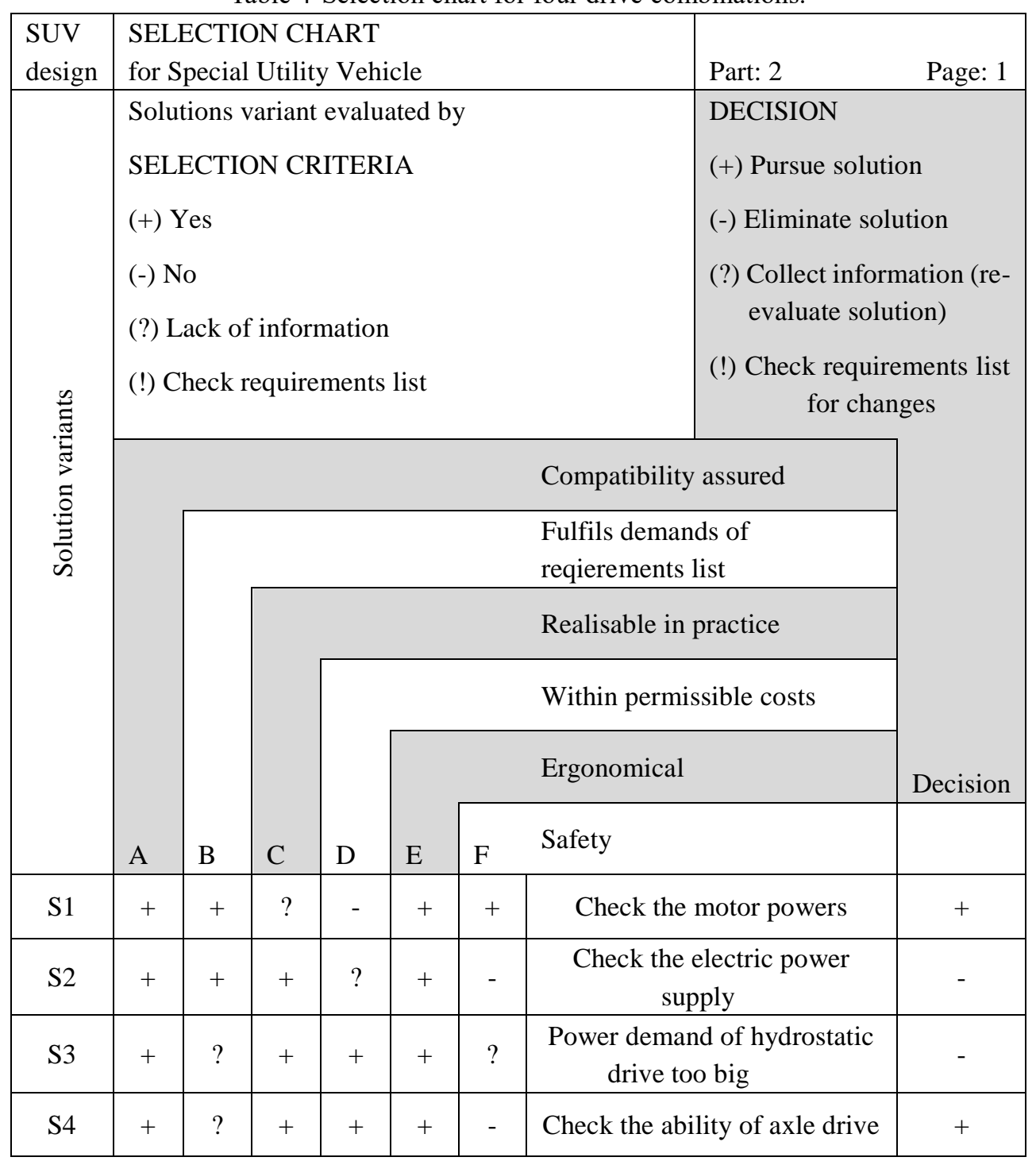




\subsection{Evaluating Principle Solution Variants}

To allow a certain decision to be made about the most suitable principle solution (concept) variant, the selected working structures have to be developed to a state that allows evaluation. This requires that for example suitable concept drawings or 3D models such as those shown in Figure 2 is produced. Rough calculations or model tests can also be useful at this stage; for example, engine power calculations, sizing of the concept, calculation of tire diameters, calculation of vehicle speed. The first stage and preliminary evaluation of the general designs that are formed by the subdesign combinations in the combination scheme are done with the selection chart. Here; Specification compliance, feasibility, reasonable cost, etc. can be used, see Table 4. Here S1 and S4 are selected as suitable solutions.

\subsection{Main Designs}

The important solutions obtained from the preliminary evaluation with the selection chart are shown in Figure 4. Solution 1 (Fig.4.a) offers a diesel motor with closed-circuit type hydrostatic drive system, 2 hydro-motor in back tyres, ergonomic design, etc. Whilst the Solution 2 (Fig.4.b) offers a gasoline motor with a hydrostatic drive, an electromechanic hand brake, reflectors and manual drive.

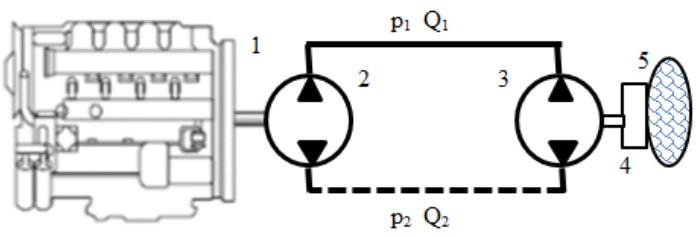

(1) Engine; (2) Drive pump; (3) Hydraulic motor;

(4) Gearbox; (5) Tyre

(a)

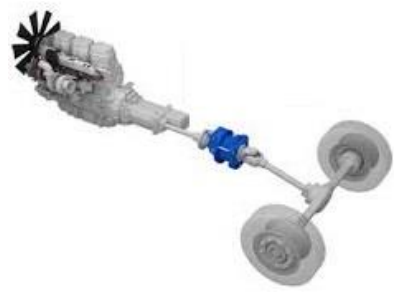

(b)

Fig. 4 Conceptual design samples of SUV: (a) Solution 1: with closed-circuit type hydrostatic drive system (b) Solution 2: axle driven vehicle.

In the design process carried out up to Stage 6 and above, some design options have been established and the result of the preliminary selection process has been identified as two of these relatively more valuable and important designs. Further to this stage, these two design samples will be evaluated more carefully and precisely and the best solution will be determined. For this purpose, some criteria and their weight factors should be determined for the conceptual design of the special utility vehicle and it's parts. Criterion determination and weight distribution jobs was made with Objectives Tree method of Pahl and Beitz (1993). The evaluation criteria organized hierarchically in the objectives tree was divided into three groups as (1) ease of use, (2) simple production and (3) safety. The subgroups are defined as easy maintenance, easy handling, simple parts production (low number of parts/complexity, use of standard parts), simple assembly, mechanical safety, overload tolerance and vibration sensitivity.

The weight coefficients given in Table 5 are determined purely based on experience. For example, when determining this one can think the evaluation criteria 'easy maintenance' and 'ease of use' may have the same importance whilst 'complexity' or 'use of standard parts' are as important as only half of them. The importance coefficients (weight) can vary from one company to another, as well as from designer to designer.

These criteria is transformed into technical parameters, where possible, the units to be assigned, and finally the two selected solutions that pass the pre-evaluation will be graded according to these parameters (Table 5). After this step, a comparison was made between the two highest-scoring solutions, with the value profile removed, and the solution that best meets these properties was chosen as the ideal solution. 
Fatma Y. Çavdar, Börklü, Kadir Çavdar and Sezer,

Journal of Advanced Mechanical Design, Systems, and Manufacturing, Vol.13, No.4 (2019)

Table 5 Selection chart for the drive combinations.

\begin{tabular}{|c|c|c|c|c|c|c|c|}
\hline \multirow[b]{2}{*}{ Evaluation criteria } & \multirow[b]{2}{*}{$\begin{array}{l}\stackrel{3}{3} \\
\stackrel{0}{0.00} \\
\frac{.00}{0} \\
3\end{array}$} & \multicolumn{3}{|c|}{ Solution 1} & \multicolumn{3}{|c|}{ Solution 2} \\
\hline & & 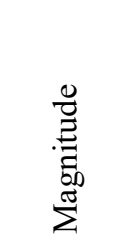 & $\frac{\mathscr{O}}{\stackrel{\pi}{\pi}}$ & 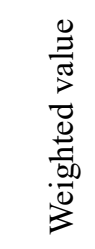 & 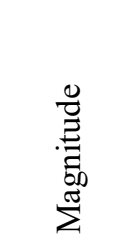 & $\frac{\mathscr{O}}{\frac{\Xi}{\sigma}}$ & 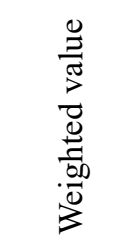 \\
\hline Easy maintenance & 0.1 & average & 6 & 0.6 & average & 4 & 0.4 \\
\hline Easy handling & 0.1 & average & 6 & 0.6 & average & 5 & 0.5 \\
\hline Ease of use & 0.1 & average & 6 & 0.6 & good & 7 & 0.7 \\
\hline Low \# of parts & 0.1 & high & 7 & 0.7 & average & 5 & 0.5 \\
\hline Complexity & 0.05 & high & 7 & 0.35 & average & 5 & 0.25 \\
\hline Standard parts & 0.05 & average & 6 & 0.3 & good & 7 & 0.35 \\
\hline Simple assembly & 0.1 & high & 7 & 0.7 & average & 6 & 0.6 \\
\hline Safety & 0.2 & high & 7 & 1.4 & good & 7 & 1.4 \\
\hline Overload tolerance & 0.1 & average & 6 & 0.6 & average & 6 & 0.6 \\
\hline Vibration sensitivity & 0.1 & average & 6 & 0.6 & average & 5 & 0.4 \\
\hline & $\Sigma \mathrm{W}=1$ & & $\Sigma \mathrm{V}_{1}=64$ & $\Sigma \mathrm{wV}_{1}=$ & & $\Sigma \mathrm{V}_{2}=57$ & $\Sigma \mathrm{wV}_{1}=5.7$ \\
\hline
\end{tabular}

\subsection{Evaluation}

After the conceptual design, Solution 1 was determined as the best solution (Figure 1). Thus, a new and innovative system has been pre-designed for the users to do the best/comfortable transportation. The most important difference is that the existing system is small (compact), addressed to user made special works, low prices and standard parts and ergonomic design.

As part of the design project of the special utility vehicle, the drive system was selected using the alternative solution matrix created in the MDA process. The alternatives here were drive systems using electricity, diesel or other fuel. Nowadays the developments in electric motors are at a very good level; however, other than the hydrostatic drive, there is no alternative drive system for special vehicles using high torque drives. Oil is transferred by means of a piston- or gear-type pump to the high-pressure hydraulic motor positioned inside the tyre. As another important task in the design and manufacturing process, the hydrostatic drive system operates without oil leakage. The best possible solution from the alternatives was then selected as the diesel motor. Diesel motors have mechanical characteristics appropriate to the drive pump characteristics. After the comprehensive engineering calculations on mechanical behaviour of the system, the diesel motor, hydraulic pump and hydraulic motors with a clutch were selected. At this time, company catalogues were consulted by the engineers. The engineering calculations were made by considering the alternatives, and mechanical determinations using FEM for the final design. 


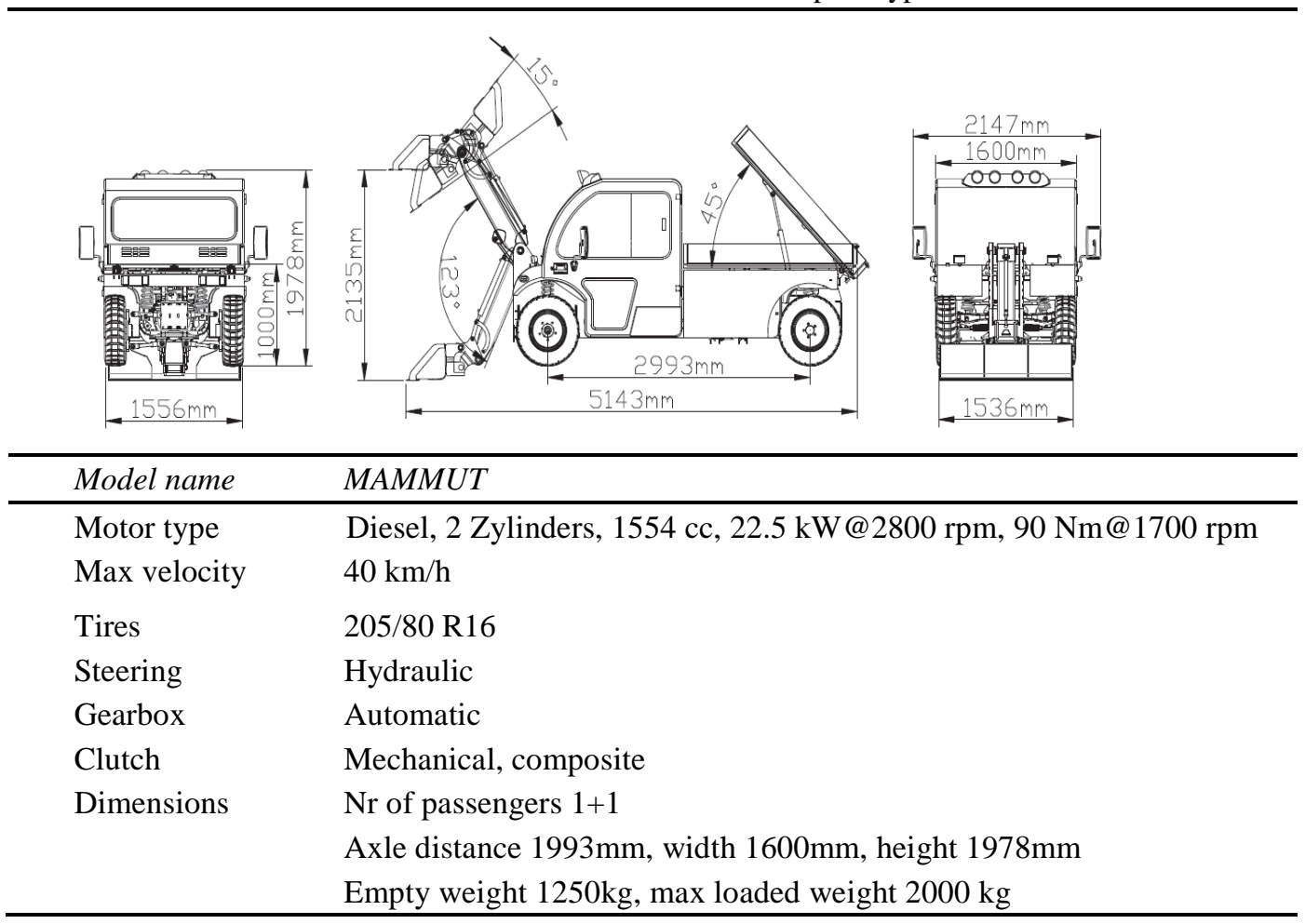

In the next step of the MDA process, the required equipment, special tools, etc. were decided upon and the assembly plans were prepared. After the completion of the purchasing process, the installation of the vehicle began. Certain design parts of the SUV, such as doors, windshield, etc., were procured from commercial suppliers. This period of the project was critical as we experienced challenges for ensuring the quality of the parts and selecting the suppliers and firms competing in the market. The installation process was successfully completed in three months. However, it should be noted here that the use of quality control techniques in the process was extremely important. These techniques are essential for SMEs which are producing the similar products. Without quality control techniques, loss of time and money may ensue.

After the manufacturing and installation processes, the function and performance tests on the vehicle prototype were conducted. The final settings and fine adjustments were carried out according to the test results, and the vehicle prototype was completed.

\section{Discussions}

The idea of the project originated from research into domestic and foreign markets. New opportunities in the domestic market were determined to be present in authors' home country, Turkey, with the potential of exporting to other countries. Since the requirements of the market were slightly different from the initial expectations of the designers, the existing product had to be improved in a way that was appropriate to the particular market circumstances, thus defining the next challenge. Many ideas were collected through brainstorming, and face-to-face meetings held with target groups for the product including agricultural firms, hotels, farmers, factories, etc. All possible requests were noted and accordingly, the requirements list was created for the product to be introduced to the market. For practical purposes, the consolidated information was converted into a spreadsheet and the list was constantly updated.

In the subsequent steps, detailed research was conducted to aid in the design and manufacture of an original product. During this period, the requirements for the pre-calculation of the engine and the drive elements were determined and carried out. Due to the large number of system elements and the limited number of project engineers, the project team encountered a wide variety of challenges. In such a case, the application of more efficient strategies were needed in order to continue with the development. One example of these strategies was holding meetings with suppliers on the shop 
floor, which was remarkably more effective than making Internet and catalogue searches or communicating by phone or via email.

Although the strategy of utilisation of standard parts was adopted, many original parts had to be designed. In this complex process, CAD techniques (Fig. 5) were applied to ensure rapid and error-free operations. The prepared spreadsheets were very useful and adaptable to the calculations of the engineering formulae. Parts of the pre-designs were analysed by finite element software and subsequently, the finalised dimensions of the parts were determined. Design and process FMEA (failure mode and effects analysis) meetings were carried out consistently. To minimize potential errors in the manufacturing and assembly stages, external services were purchased from experienced companies. This method was well managed by the project team and positive results were obtained. After a long and arduous working phase, the prototype was brought to the industrialisation stage.
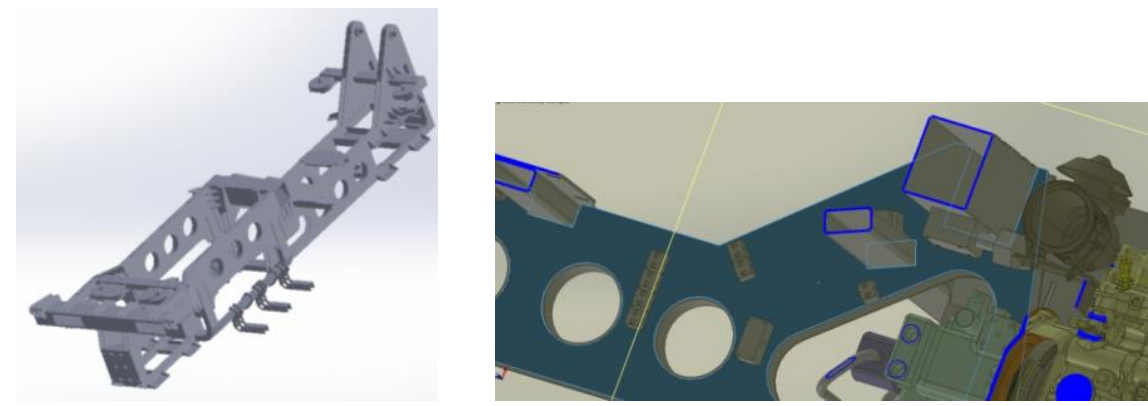

Fig. 5 Sample computer models: (left) the main chassis design; (right) the hydraulic pipe plumbing through main road design

\section{Experienced MDA Opportunities}

Small-sized companies have relatively fewer employees and due to limited financial resources the employees usually have lower qualifications. Hence, the desired success in the design and manufacturing processes of complex projects is difficult to achieve. However, by using a systematic approach such as the MDA, complex projects can be managed and completed successfully even with a small number of employees. In order of importance, the criteria for successful completion of a project were found to be existing engineering experience and availability of computer-aided engineering tools; however, motivation of the team was a prerequisite for achieving the desired results.

As the outcome of this project, a particular type of special utility vehicle was designed and produced for the first time in Turkey. Most importantly, a great deal of information and experience was obtained. After the MDA design process, many innovative ideas were gathered for the next potential vehicle type, a smaller version of the existing prototype. Moreover, the data regarding quality standardisation, manufacturing duration, and costs, as well as the root cause of the failures that occurred during application were examined. The performance data of the vehicle and the hydrostatic power values of the driving system constitute quite valuable information in this field and have been stored in company memory.

Small companies can design and manufacture complex products using the MDA. In this way, new products will have an expanded performance arena and greater environmental compliance in addition to being more cost effective and ergonomic. For example, in this study, production costs were lowered by $20 \%$ and fuel consumption by $10 \%$ compared to similar conventional vehicle production and the developed vehicle was more than $10 \%$ lighter. The overall approach and the specific methods described by the MDA have been applied many times to solve problems in industry. As a result of using the MDA, small companies can design and produce original products economically, and they can develop commercially successful products. In particular, they can increase their registered patents. They can also find better solutions for complex products in shorter development time. One particular achievement of the MDA is that young engineers, once they are taught the approach and methods, can contribute to a company surprisingly quickly, without first having to gain extensive experience. And finally, future project processes will be easier and more effective.

Finally, it can be said that MDA has appropriate methods for conceptual design, and it simplifies the process with minimum deficiency. However, MDA is inadequate in the creation of solutions and development phases. For these 
Fatma Y. Çavdar, Börklü, Kadir Çavdar and Sezer,

Journal of Advanced Mechanical Design, Systems, and Manufacturing, Vol.13, No.4 (2019)

operations, engineering experience and talent should be introduced. The design experience that each engineer or company has gained over time will lead them through this process.

\section{Conclusions}

A particular type of special utility vehicle was designed and produced using MDA. A great deal of information and experience gained throughout the design and prototype manufacturing process has been shared and discussed in detail. Valuable data regarding quality standardisation, manufacturing lead time, costs, as well as the root cause of the failures were examined. It has been shown that challenges in competitive design problems can well be managed and solved using the systematic approach of the MDA with the restricted resources and the manpower. The use of MDA in a small-scale company especially in the conceptual design stage provides great benefits. Such great scale projects cannot be achieved in small companies without the MDA.

\section{References}

Babalik, F.C. and Cavdar, K., Machine Elements and Design Applications (2014), p.9, Dora publishing (in Turkish).

Blizzard, J.L. and Klotz, L.E., A framework for sustainable whole systems design, Design Studies, Vol.33, No.5 (2012), pp.456-479.

Burr, H., Vielhaber, M., Deubel, T., Weber, C. and Haasis, S., CAx/engineering data management integration: enabler for methodical benefits in the design process, Journal of Engineering Design, Vol.16, No.4 (2005), pp.385-398.

Cavdar, K., Noiseless Machine Design (2000), p. 12, PhD Thesis, Uludag University, Turkey (in Turkish).

Chen, D.Y., Wang, L.M., Wang, C.Z., Yuan, L.K., Zhang, T.Y. and Zhang, Z.Z., Finite element based improvement of a light truck design to optimize crashworthiness, Int. J. Automotive Technology, Vol.16, No.1 (2015), pp.39-49.

Eder, W.E., Case Study in Design Engineering, Proceedings of the Canadian Design Engineering Network (CDEN 06) (2006), pp.332-338.

Günther, J. and Ehrlenspiel, K., Comparing designers from practice and designers with systematic design education, Design Studies, Vol.20, No.5 (1999), pp.439-451.

Heylighen, A. and Bianchin, M. How does inclusive design relate to good design? Designing as a deliberative enterprise, Design Studies, Vol.34, No.1 (2012), pp.93-110.

Kim M.S., Kang D.O. and Heo S.J., Innovative design optimization strategy for the automotive industry, Int. J. Automotive Technology, Vol.15, No.2 (2014), pp.291-301.

Koller, R., Konstruktionslehre für den Maschinenbau (1985), p. 105, Springer Verlag (in German).

Ma C., Ko S.Y., Jeong, K.Y. and Kim, H.S., Design methodology of component design environment for PHEV, Int. J. Automotive Technology, Vol.14, No.5 (2013), pp.785-795.

Mayda, M. and Choi, S.K., A reliability-based design framework for early stages of design process, J. of the Brazilian Society of Mechanical Sciences and Engineering, Vol.39, No.6 (2017), pp.2105-2120.

Pahl, G. \& Beitz, W.,Konstruktionslehre (1993), p. 1-10, Springer Verlag, (in German)

Pahl, G., Beitz, W., Feldhusen, J., Grote, K. H., Engineering design: a systematic approach (2007), p. 103-110, Springer Pub.

Rodenacker, W.G., Methodisches Konstruieren (1991), p. 5, Springer Verlag (in German).

Sahoo S., Subramanian S.C., Mahale N. and Srivastava S., Design and development of a heading angle controller for an unnamed ground vehicle, Int. J. Automotive Technology, Vol.16, No.1(2015), pp.27-37.

Smith J. and Clarkson P.J., A method for assessing the robustness of mechanical designs, Journal of Engineering Design, Vol. 16, No.5 (2005), pp.493-509.

Yoon Y.S., Kim S.J. and Kim K.S. Conceptual design of economic hybrid vehicle system using clutchless geared smart transmission, Int. J. Automotive Technology, Vol.14, No.5 (2013), pp.779-784. 